\author{
Marcin DEREŃ ${ }^{1}$
}

\title{
STANOWISKO SYMULACYJNE DO BADANIA GLOWIC OPTOELEKTRONICZNYCH
}

\begin{abstract}
Latające platformy bezzałogowe (UAV) znajdują obecnie coraz więcej zastosowań zarówno militarnych jak i cywilnych. Jednym z częściej wykonywanych zadań jest szeroko rozumiana obserwacja. Podczas jej prowadzenia wykorzystuje się różnego rodzaju sensory, często w postaci głowic optoelektronicznych - kamer umieszczonych w układzie mechatronicznym, umożliwiającym zmianę orientacji sensora (kamery) względem nosiciela. Projektując algorytmy sterowania głowicy optoelektronicznej należy uwzględnić szereg parametrów związanych nie tylko bezpośrednio z konstrukcją tej głowicy, ale również z warunkami jej pracy i możliwościami nosiciela. W artykule przedstawiono podstawowe informacje o głowicach optoelektronicznych, ze szczególnym uwzględnieniem głowicy dwuosiowej, prze-znaczonej do instalacji na pokładzie platformy bezzałogowej. Przedstawiono stanowisko do badań symulacyjnych głowic optoelektronicznych, zrealizowane z wy-korzystaniem pakietu Matlab/Simulink. Umożliwia ono badanie algorytmów sterowania poprzez symulację zachowań nosiciela. Stanowisko umożliwia zadawanie parametrów na podstawie wcześniej zarejestrowanych rzeczywistych lotów platformy bezzałogowej, jak również stosowanie sztucznych, niespotykanych w locie wymuszeń.
\end{abstract}

Słowa kluczowe: głowica obserwacyjna, gimbal, UAV, stabilizacja,symulacja

\section{Głowica optoelektroniczna}

Jednym z najczęściej stosowanych rozwiązań wykorzystywanych do zadań szeroko pojętej obserwacji są głowice optoelektroniczne, określane potocznie mianem gimbali. Głowica taka to kamera, lub zestaw kilku kamer umieszczonych na mechanicznej platformie umożliwiającej obrót sensora względem podstawy. Głowice projektuje się przyjmując odpowiednie założenia, co do ich przyszłego wykorzystania, uwzględniając również możliwości nosiciela (platformy bezzałogowej). Należy uwzględnić nie tylko gabaryty platformy (wpływające na wielkość głowicy, a tym samym możliwości zastosowania sensorów) ale również jej zdolności manewrowe, a nawet rodzaje planowanych misji.

\footnotetext{
${ }^{1}$ Marcin Dereń, Eurotech sp. z o.o. 39-300 Mielec, ul. Strefowa 3, m.deren@eurotech.com.pl
} 


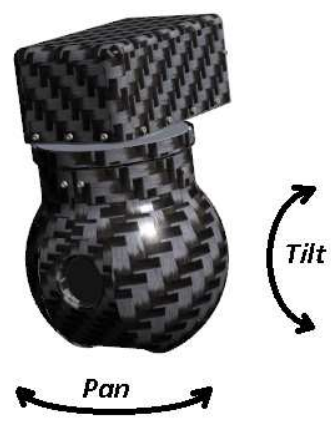

Rys. 1. Kierunki obrotów dwuosiowej głowicy obserwacyjnej

Fig. 1. Rotation directions of two-axis gimbal

Jednym z podstawowych rozwiązań są głowice $\mathrm{z}$ dwiema osiami obrotu (rys. 1): w osi azymutu (nazywanej pan) oraz osi elewacji (nazywanej tilt) z przynajmniej jedną kamerą z możliwością przybliżania obrazu (zoom). Rozwiązanie takie jest stosunkowo prostym a jednocześnie uniwersalnym, zapewniającym szerokie spektrum możliwych realizacji działań. Większość oferowanych układów sterowania dla platform bezzałogowych przewiduje w swej transmisji sterowanie przynajmniej tymi trzema wielkościami. Dotyczy to również standardów militarnych [1].

\section{Sterowanie i podstawowe tryby pracy głowicy dwuosiowej}

\subsection{Sterowanie głowicą optoelektroniczną}

Sterowanie głowicą optoelektroniczną możemy rozpatrywać na dwóch poziomach.

Na poziomie niższym mówimy o sterowaniu poszczególnymi napędami, z uwzględnieniem dynamiki silników oraz zastosowanych przekładni. Rozpatrujemy wtedy głowicę jako zespół napędów, lub nawet serwomechanizmów zdolnych zapewnić odpowiedni ruch w wybranych osiach głowicy. Zapewnić należy odpowiednie sygnały sterujące, zależne od zastosowanych silników (np. PWM, dla silników DC, odpowiednia częstotliwość kroków dla silników krokowych), oraz pożądanych parametrów pracy - najczęściej uzyskania odpowiednich prędkości kątowych, lub dokładności pozycji danej osi.

Na poziomie wyższym nie zajmujemy się sterowaniem silnikami a sterowaniem wektora LOS (Line of Sight) - wektora kierunku ,patrzenia” głowicy. $\mathrm{Tu}$, w zależności od rodzaju sterowania, istotna staje się orientacja sensora względem podstawy (nosiciela) oraz względem nieruchomego układu związanego z ziemią. Na tym poziomie wypracowywane są wartości zadawane sterowań dla poziomu niższego, tak by utrzymać, lub uzyskać odpowiednie ukierun- 
kowanie wektora LOS. Można tu rozpatrywać różne tryby pracy głowic (punkt 2.2)

Równolegle do tych dwóch poziomów sterowania możemy wyróżnić również sterowanie zainstalowanym sensorem, które wpływa pośrednio na parametry algorytmów sterowania (np. poprzez modyfikację prędkości obrotowych głowicy, w zależności od aktualnego powiększenia/przybliżenia kamery).

\subsection{Tryby pracy}

Z punktu widzenia operatora, platforma UAV i głowica optoelektroniczna stanowią zespół urządzeń będących narzędziem pracy. Należy pamiętać, że lot platformy wykonywany jest $\mathrm{w}$ ściśle określonym celu i (w przypadku zadań szeroko pojętej obserwacji) operator nie zajmuje się pilotażem a uzyskaniem określonych danych z obserwowanego obrazu. Operator obserwuje obraz przekazywany z głowicy i na jego podstawie steruje obrotami osi, tak by osiągnąć zamierzony cel (np. ciągła obserwacja danego obiektu). Operator staje się w ten sposób elementem pętli sterowania głowicy.

Tryby pracy głowic są dostosowane do specyfiki realizowania misji, stąd dostępne na rynku głowice zapewniają minimum 2 tryby pracy: tryb prędkościowy ze stabilizacją żyroskopową, oraz tryb pozycyjny. Należy zauważyć, że różni producenci udostępniają również inne tryby pracy (np. geopointing, czyli kierowanie wektora LOS w kierunku określonych współrzędnych geograficznych), jednak dwa wymienione powyżej tryby są najpowszechniejsze i bez nich niemożliwa byłaby realizacja wielu misji obserwacyjnych.

Tryb pozycyjny jest wykorzystywany rzadziej. W trybie tym operator zadaje ustawienie kątów głowicy na określone wartości i wektor LOS jest utrzymywany jako stały względem nosiciela. Tryb ten najczęściej wykorzystuje się podczas lotu w trybie widoku pilota (ang. PilotView). Polega ona na prowadzeniu obserwacji w kierunku lotu platformy, wykorzystywanego podczas startów i lądowań, w sytuacjach awaryjnych, lub podczas lotu ręcznego (pod pełną kontrolą operatora).

Tryb sterowania prędkościowego ze stabilizacją wykorzystywany jest znacznie częściej niż tryb pozycyjny. W trybie tym operator zadaje kierunki i prędkości obrotu głowicy, nie zważając na pozycję kamery, a jedynie na obserwowany obraz, tak by wektor LOS cały czas skierowany był na obserwowany obiekt. Na uzyskiwane prędkości kątowe głowicy wpływ ma nie tylko operator (poprzez wychylenie manipulatora), ale również - co zapewnia człon stabilizacji - prędkości kątowe nosiciela, oraz zoom sensora. W przypadku prędkości kątowych nosiciela chodzi o wyeliminowanie ich wpływu (przeciwdziałanie obrotom), zaś w przypadku zoom, chodzi o odpowiednie zmniejszenie prędkości kątowych w ruchu głowicy dla dużych przybliżeń. 


\section{Wektor LOS}

Wektor LOS jako kierunek patrzenia kamery określany jest w układzie współrzędnych związanym z ziemią. Wpływ na niego ma zarówno zmiana kątów osi głowicy (pan i tilt), jak i orientacja nosiciela.
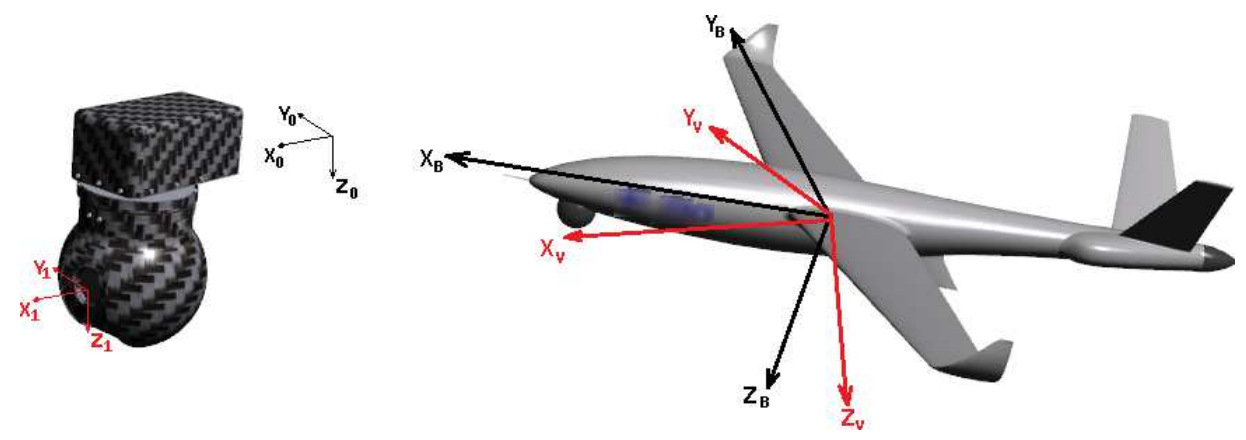

Rys. 2.Układy współrzędnych do wyznaczenia wektora LOS dla głowicy i nosiciela.

Fig. 2. Coordinate systems for determining gimball and carrier LOS vector

Przyjmijmy układy współrzędnych jak na rys 2. Układ $\mathrm{XYZ}_{1}$ związany jest $\mathrm{z}$ kamerą, natomiast $\mathrm{XYZ}_{0} \mathrm{z}$ podstawą, tym wypadku z nosicielem. Takie rozmieszczenie układów współrzędnych jest związane ze sposobem montażu. Głowica jest montowana na spodzie nosiciela, co nie jest jedynym możliwym rozwiązaniem. Macierz obrotu układu $\mathrm{XYZ}_{1}$ względem układu $\mathrm{XYZ}_{0}$ (po uwzględnieniu obrotu wokół dwóch osi: Pan (P) i Tilt (T)) jest równa:

$$
R_{G O}=\left[\begin{array}{ccc}
\cos P \cos T & \sin P \cos T & -\sin T \\
-\sin P & \cos P & 0 \\
\cos P \sin T & \sin P \sin T & \cos T
\end{array}\right]
$$

Wektor obserwacji kamery w układzie $\mathrm{XYZ}_{0}$ można wyznaczyć jako:

$$
\vec{L}=\left[\begin{array}{l}
x \\
y \\
z
\end{array}\right]=R_{G O}^{T}\left[\begin{array}{l}
1 \\
0 \\
0
\end{array}\right]=\left[\begin{array}{c}
\cos P \cos T \\
\sin P \cos T \\
-\sin T
\end{array}\right]
$$

Przyjmując, że głowica jest na platformie zamontowana tak, że kierunek osi $\mathrm{X}_{0}$ wskazuje dziób samolotu, zaś kierunek osi $\mathrm{Y}_{0}$ prawe skrzydło wektor $\mathrm{L}=[1,0,0]^{\mathrm{T}}$ oznacza orientację osi optycznej kamery $\mathrm{w}$ kierunku zgodnym z kierunkiem lotu, $\mathrm{L}=[0,1,0]^{\mathrm{T}}$ oznacza obserwację na prawe skrzydło, zaś $\mathrm{L}=[0,0,1]^{\mathrm{T}}$ oznacza kierunek patrzenia w dół platformy. 
Macierz obrotu dla nosiciela (wyznaczająca orientację układu $\mathrm{XYZ}_{\mathrm{B}}$ w układzie związanym z ziemią $X Y Z_{V}$ ) jest równa [2]:

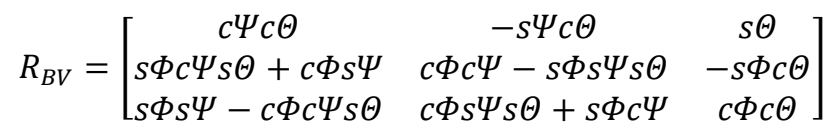

gdzie:

$$
\begin{gathered}
c \Phi=\cos (\Phi), s \Phi=\sin (\Phi), \\
c \Theta=\cos (\Theta), s=\sin (\Theta), \\
c \Psi=\cos (\Psi), s \Psi=\sin (\Psi)
\end{gathered}
$$

to cosinusy i sinusy kątów Eulera odpowiednio przechylenie, pochylenie i odchylenie platformy UAV, (kolejne obroty wokół osi $x, y, z$ ). Na podstawie równań 1-3 wektor LOS wyrażony w układzie związanym z ziemią ma postać:

$$
\overrightarrow{L O S}=\left[\begin{array}{l}
r_{x} \\
r_{y} \\
r_{z}
\end{array}\right]=\left(R_{G O} R_{B V}\right)^{T}\left[\begin{array}{l}
1 \\
0 \\
0
\end{array}\right]
$$

co daje kolejne współrzędne wektora:

$$
\begin{gathered}
r_{x}=(c(\Psi) c(\Theta) c(P)+(s(\Phi) c(\Psi) s(\Theta)-c(\Phi) s(\Psi)) s(P)) c(T)- \\
(s(\Phi) s(\Psi)+c(\Phi) s(\Psi) s(\Theta)) s(T) \\
r_{y}=(s(\Psi) c(\Theta) c(P)+(s(\Phi) s(\Psi) s(\Theta)+c(\Phi) c(\Psi)) s(P)) c(T)- \\
(c(\Phi) s(\Psi) s(\Theta)-s(\Phi) c(\Psi)) s(T) \\
r_{z}=(s(\Phi) c(\Theta) s(P)-s(\Theta) c(P)) c(T)-c(\Phi) c(\Theta) s(T)
\end{gathered}
$$

Współrzędne te uwzględniają obrót głowicy oraz nosiciela, i są wyrażone w układzie związanym z ziemią. Ich określenie umożliwia weryfikację modelu oraz algorytmów stabilizacji głowicy. Dla stabilizacji głowicy musi zostać wypracowane takie sterowanie, aby wektor LOS pozostał stały podczas zmiany orientacji nosiciela. 


\section{Stanowisko symulacyjne do badań Hardware in the Loop}

Skutecznym testem dla opracowanej głowicy i algorytmów sterowania jest jej montaż na platformie docelowej i wykonanie lotu z profilem misji zbliżonym do przewidywanego. Niestety, podejście takie jest kosztowne i kłopotliwe (zwłaszcza w przypadku większych UAV). Innym sposobem testowania jest budowa modelu matematycznego i symulacja zachowań głowicy. Budowa dokładnego modelu dynamiki nie jest jednak zadaniem trywialnym, a dokładna symulacja wymaga również modelu symulacyjnego platformy i prowadzonej misji. Możliwym jest również zainstalowanie głowicy na stole obrotowym, lub ramieniu robota [3] by w ten sposób wymusić przyspieszenia i prędkości kątowe. Niejako pośrednim sposobem testowania algorytmów sterowania jest wykonanie stanowiska HIL (ang. hardware in the loop). Na takim stanowisku oprogramowanie sterujące jest uruchamiane na docelowej platformie sprzętowej, z symulowaniem modelu sterowanego procesu. Stanowiska HIL pozwalają sprawdzić reakcje rzeczywistego układu sterowania w symulowanym otoczeniu, co wpływa na ich szerokie stosowanie w technice lotniczej [4], jako tańszą alternatywę dla wykonywania badań w locie.

\section{1. xPC Target (Simulink Real-Time)}

Pakiet Matlab/Simulink zawiera oprogramowanie Simulink Real-Time [5] (we wcześniejszych wersjach, w tym w wersji wykorzystywanej przez autora, udostępnianego jako xPC Target). Środowisko to pozwala na implementację algorytmu lub modelu symulacyjnego w środowisku Simulink na komputerze (hoście), po czym jego wykonanie na dedykowanym komputerze docelowym (xPC Target) z fizycznie dołączonymi elementami systemu. Umożliwia to przygotowanie symulacji, przeprowadzenie testów hardware in the loop, a także szybkie prototypowanie algorytmów. Komunikacja pomiędzy komputeremhostem, a komputerem docelowym odbywa się poprzez interfejs ethernetowy, umożliwiając nie tylko programowanie układu xPC Target, ale również podgląd i wizualizację parametrów na komputerze host.

\subsection{Stanowisko testowe}

Wykorzystywane stanowisko (przedstawione schematycznie na rys. 3) składa się z komputera klasy PC z oprogramowaniem Matlab/Simulink, komputera PC (pracującego jako xPC target), głowicy optoelektronicznej (z własnym mikrokontrolerem sterującym) oraz opcjonalnego rejestratora CAN [6]. 


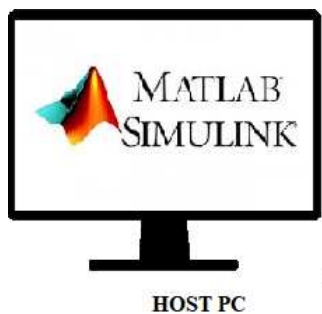

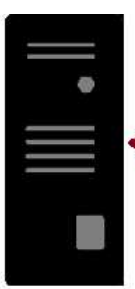

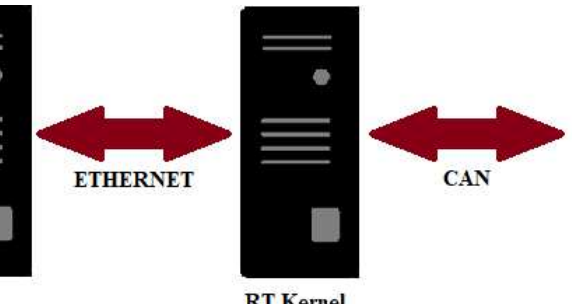

RT Kernel

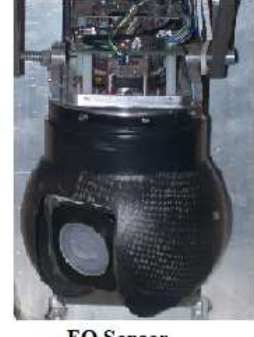

EO Sensor

Rys. 3. Schemat ogólny stanowiska testowego

Fig. 3. General scheme of the test stand

Komputer PC pełni rolę hosta. xPC target w prezentowanym rozwiązaniu jest komputerem umożliwiającym przeprowadzenie symulacji opracowanych algorytmów w czasie rzeczywistym z uwzględnieniem odpowiedzi fizycznego obiektu sterowania. Nie jest planowany jako docelowa platforma sterująca, ale jako główne narzędzie do przeprowadzenia symulacji i doboru algorytmów. Komunikacja pomiędzy hostem a xPC odbywa się poprzez interfejs ethernet, natomiast pomiędzy xPC, a głowicą optoelektroniczną poprzez interfejs CAN. Całość komunikacji poprzez interfejs CAN jest dodatkowo rejestrowana do późniejszej analizy offline. Taka budowa stanowiska umożliwia badanie algorytmów na obu poziomach sterowania głowicą, przy czym nie narzuca docelowego rozwiązania sprzętowego dla głowicy optoelektronicznej. Dodatkowo możliwe jest przeprowadzenie symulacji z udziałem innych komponentów połączonych do wspólnej magistrali CAN, np. w celu sprawdzenia ich wzajemnej interakcji. Algorytmy opracowywane są na komputerze PC (host), po czym wgrywane i wykonywane na komputerze xPC target, do którego trafiają również dane $\mathrm{z}$ głowicy. Umożliwia to nie tylko sprawdzenie działania projektowanych algorytmów, ale również porównanie posiadanego/opracowanego modelu symulacyjnego z rzeczywistym obiektem.

\subsection{Wybrane realizacje}

W przypadku sterowania niższego poziomu na komputerze PC opracowane zostały algorytmy sterowania napędami. Wartości zadawane są ustawiane przez operatora za pośrednictwem interfejsu CAN. Trafiają one na wejście regulatorów realizowanych w komputerze xPC target. Wyjścia z regulatorów (również poprzez magistralę CAN) trafiają do głowicy optoelektronicznej gdzie mikrokontroler wystawia zadane sygnały sterujące (wyznaczone w xPC Target), oraz dokonuje odczytu aktualnej pozycji, a także prędkości osi głowicy. Wartości te trafiają do xPC (ponownie przez magistralę CAN) tworząc pętlę sprzężenia zwrotnego. Mikrokontroler w głowicy pełnił w tym przypadku jedynie rolę 
układu pomiarowego oraz generujacego zadany sygnał PWM do sterowania pracą silników. Na tym poziomie możliwe jest przeprowadzenie identyfikacji poszczególnych osi jako obiektów sterowania, dobór algorytmów sterowania napędami oraz ich parametrów. Dzięki zastosowaniu do tego stanowiska z oprogramowaniem Matlab/simulink możliwe było szybkie przetestowanie różnych regulatorów, $\mathrm{z}$ różnymi parametrami działania. Umożliwia to również budowę modelu zachowania napędów głowicy poddanych różnym wymuszeniom. Dobrane w ten sposób regulatory zostały następnie zaimplementowane w języku C i posłużyły do zaprogramowania mikrokontrolerów sterujących napędami głowicy. Na rysunku 4 przedstawiono wynik jednej z prób identyfikacji parametrów dynamicznych osi Pan. Wykres 1 przedstawia zadawane wymuszenia w postaci wypełnienia PWM (przy czym ujemna wartość oznacza zmianę kierunku obrotów). Wykres 2 przedstawia odpowiedź głowicy w postaci kąta obrotu osi Pan wyrażonej w impulsach enkodera (jako wartości mierzonej bezpośrednio).

W przypadku sterowania wyższego poziomu, w układzie HIL jak poprzednio, możliwe jest przetestowanie algorytmów stabilizacji. W tym wypadku komputer xPC target służył do symulacji zachowania nosiciela. Dla podstawowych algorytmów stabilizacji sygnałami wejściowymi są orientacja przestrzenna $(\Phi, \Theta, \Psi)$ oraz prędkości kątowe nosiciela $(\mathrm{P}, \mathrm{Q}, \mathrm{R})$, a sygnałami wyjściowymi odpowiedź głowicy w postaci zmiany kątów pan oraz tilt, co umożliwia określenie wektora LOS, oraz określenie dokładności algorytmu. Dzięki zastosowaniu HIL możemy zadać wymuszenia nie występujące w rzeczywistym locie, w celu sprawdzenia poprawności działania stabilizacji w pojedynczej osi, co ułatwia zaobserwowanie działania algorytmu. W kolejnych etapach testowania łatwo można dodać niezerowe wartości prędkości w pozostałych osiach i badanie poprawności zachowania algorytmów stabilizacji. Należy zauważyć, że dzięki symulacji możliwe jest podanie wymuszeń niezakłóconych, jak i obarczonych szumem. Wreszcie możliwe jest również podanie na wejście wcześniej zarejestrowanych parametrów rzeczywistego lotu i sprawdzenie działania głowicy, oraz porównania rzeczywistych odpowiedzi z opracowanym modelem.

Należy zaznaczyć, że stanowisko symuluje dla głowicy jej sensory prędkości kątowych i przyspieszeń, zatem wymaga poprawnego przygotowania danych, z uwzględnieniem wpływu zmiany orientacji nosiciela. 


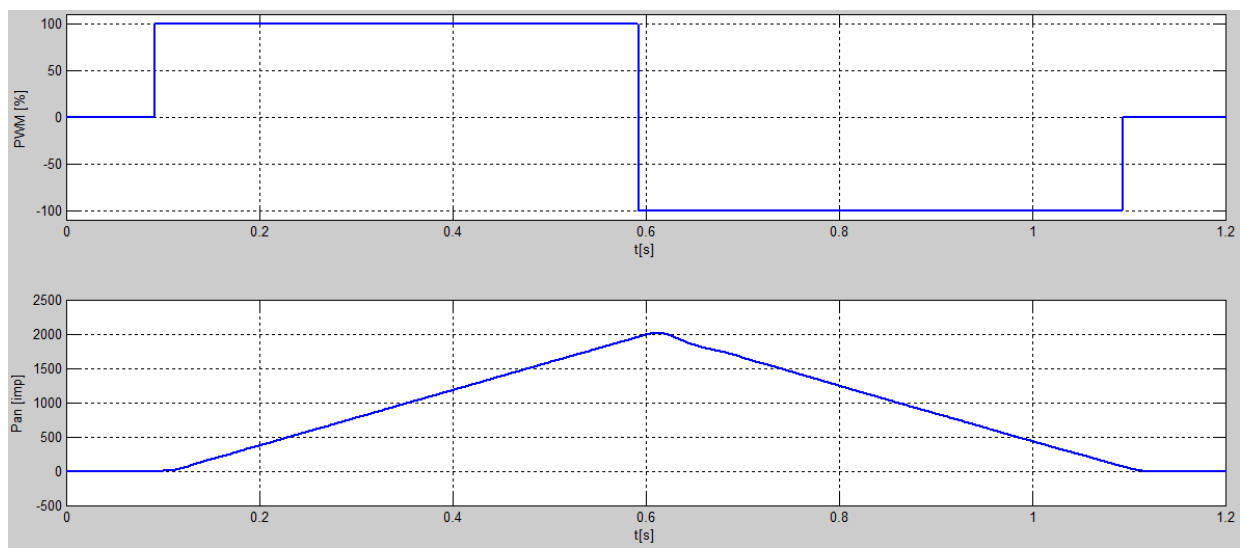

Rys. 4. Fragment przebiegów uzyskanych w trakcie prób identyfikacji osi Pan

Fig. 4. Fragment of the waveforms obtained during the Pan axis identification test

\section{Podsumowanie}

Zaprezentowane stanowisko do badań głowic optoelektronicznych jest pośrednim rozwiązaniem w badaniu, pomiędzy próbami w locie a przeprowadzeniem wyłącznie symulacji opartej na modelu matematycznym głowicy. W przypadku dostępu do oprogramowania Matlab/simulink real time umożliwia przeprowadzenie szeregu symulacji zarówno dla sztucznych jak i rzeczywiście występujących wymuszeń. Wadą rozwiązania jest niemożliwość sprawdzenia rzeczywistych czujników prędkości kątowych i przyspieszeń, jednak dla sprawdzenia poprawności działania algorytmów nie stanowi to powodu do dyskwalifikacji.

\section{Literatura}

[1] STANAG 4586, STANDARD INTERFACES OF UAV CONTROL SYSTEM (UCS) FOR NATO UAV INTEROPERABILITY.

[2] Bociek S., Gruszecki J.: Układy sterowania automatycznego samolotem. Oficyna Wydawnicza Politechniki Rzeszowskiej, Rzeszów 1999.

[3] Machowski B., Panasiuk K.: Wykorzystanie robota przemysłowego do badania układu stabilizacji głowicy śledzącej, Mechanik, nr 7/2011, s. 521-526.

[4] Chudy P., Dittrich P., Vlk J., Rzucidlo P., HW in-the-loop simulation of light aircraft's autopilot, AIAA Modeling and Simulation Technologies (MST) Conference, August 19-22, Boston, MA, 2013.

[5] https://www.mathworks.com/products/simulink-real-time.html (dostęp 15.08.2017).

[6] Dereń M.: A miniature on-board data recorder for unmanned platform, ZN PRz Mechanika, 87, 2015, s. 17-22. 


\section{TEST STAND FOR ELECTRO-OPTICAL GIMBAL SIMULATION TEST}

\section{S u m m a r y}

Unmanned aerial vehicles (UAV) function in a growing number both military and civil applications. One of commonly undertaken tasks is an observation in its broadest sense. The observation involves using different kinds of sensors which often take form of electro-optical gimbals i.e. cameras placed in a mechatronic system which enables change of camera orientation toward a carrier. Developing control algorithms for the electro-optical gimbals as well as for the cameras, one should consider a number of parameters connected not only with the construction of the gimbal but also with its work conditions, especially including the capabilities of the carrier. The article presents the elementary information on the electro-optical gimbal, with special emphasis on a two axis gimbal dedicated to installing on board UAV. The designed and realized test stand for electro-optical gimbals simulation tests, which have been perfomed with the use of Matlab/Simulink, is also described in the article. The test stand allows testing the control algorithms via simulation of carrier behavior. It also enables parameterization on the basis of recorded UAV real flights as well as using forced set values not existing during real flights.

Keywords: electro-optical systems, gimbal, UAV, stabilization, simulation

DOI: $10.7862 /$ re. 2017.8

Tekst złożono w redakcji: wrzesień 2017

Przyjęto do druku: październik 2017 